\title{
LITERACY, EDUCATION AND HEALTH DEVELOPMENT: RESEARCH PRIORITIES
}

\author{
ROBERT N. GROSSE \\ Department of Health Planning and Administration, School of Public Health, University of Michigan, \\ Ann Arbor, Michigan 48109, U.S.A.
}

\begin{abstract}
How education and health are linked in developing countries and what educational activities produce change are quite uncertain. Questions for research on these concerns are noted, and it is suggested that prospective longitudinal studies, household surveys, and field observations might well be added to the more usual multivariate analyses of records. Analyses of educational program implementation alternatives are also suggested.
\end{abstract}

In considering literacy or education, we should be conscious that we may be and likely are dealing with a proxy or indicator of something more fundamental. Education's main role may not be through a "pure" effect or working through other variables, but rather as a useful index of complex social changes.

Policies directed only at indicators themselves may result in relatively ineffective or unintended consequences, and even damage their usefulness as indicators by reducing historic levels of correlation. Infant mortality rates have long been regarded as indicators of environmental conditions, of social and economic development, and of the quality and accessibility coverage of health services. This does not mean that policies specifically designed to reduce infant mortality will have the effect of or work only through influencing the more general environmental, developmental, or health considerations. Intensive care units for high-risk infants may reduce infant mortality without a more general effect, except possibly a negative one flowing from high opportunity costs.

There is as yet little evidence that changes in policies with respect to education bring about changes in health status, or even that changes in the amount or distribution of education result in health status changes. Since World War II, there has been a revolution in life expectancy and a revolution in educational coverage. Each may have been caused by the same set of factors or interact in both directions. Ram and Schultz (1979) have 
suggested that increasing investments in education in India may have resulted from increasing life expectancies.

That education, however it has been measured, and health status, usually measured in some mortality or life expectancy dimension, are somehow closely linked seems evident. How they are linked and what activities will make a real difference remain uncertain.

One question is whether education is a productive precondition or complement to the effectiveness of other usually suggested interventions.

Education appears to have both complementary and substitutive relationships with preventive and curative health services (and probably with other social activities). Research is needed to understand the relationship of social policy variables including education to the effectiveness of health interventions such as water supply, drainage, fecal waste disposal, immunization, drug supplies, rural medical care units, and nutrition and nutrition behavior interventions. Examination of education in the absence of consideration of other social variables may mean we learn only about the net effect of the sum of them.

A second question (or set of questions) is how does education affect behavior or earning power and which of these changes influences health status and how and by how much? The effects of education may be so many apart from those on health, that the matter of cost-effectiveness requires that possible significant impacts other than those on health also need to be taken into consideration.

We need to know more about what kinds of education (in specitic settings) affect health and to what extent. Are people better off if the focus is on school attendance -- and what dimensions - time, attainment, etc.? What are the effects of adult literacy training and of informal education? And what measures of education impact are useful - skills, attitudes, attainment of credentials? Who are the significant targets - rural, urban, poor, women, others?

Although we have perhaps fewer choices of health measures, are we concerned with mortality, morbidity, disability, or nutritional status, or what? While in general in LDC's morbidity and mortality seem to be closely associated, there appear to be differences in the ranking of interventions as effectiveness dimensions change. Sanitation, for example, may seem preferable in terms of costs and effects in reducing morbidity and disability days. But some forms of curative medical care such as oral rehydration or immunizations and nutrition programs seem preferred when mortality is the measure of effectiveness. Total resource constraints - budgets - may also affect preferred policy design.

One additional caution: in general, we have been demonstrating that 
education is associated with health improvements. But there have been negative results associated with educational interventions. One possible effect of education in rural areas has been to "spoil" children for careers in agriculture and influence migration to cities. While we have not related urban health problems to education, we have social problems intensified by education which may be inappropriate to the goals and needs of the population as a whole.

It would seem that the time has come to allocate significant research resources to special prospective longitudinal studies using variables which are determined by policy research needs. Analysis limited to existing data sets may lead us to poor proxies or to irrelevant or unreliable data for developing relationships of interest.

Records and reports are usually unreliable sources of population descriptions in epidemiologic research in developing countries. Special studies of the population such as household surveys are usually a major improvement in that they are more likely to be relevant: that is, they survey what happens in the population other than the events in clinics or hospitals. There may be analogous problems in the use of other recorded data, even in censuses. Further, census data will not usually give us directly what may be wanted with respect to either policy variables or intermediate variables or mechanics or dependent variables.

There are several methods of inquiry, each of which may play roles in generating hypotheses, testing hypotheses, and designing alternative policies for analysis. Among these are analyses of quantitative variables, model building (epidemiological and behavioral), and the kind of insights gained by anthropological observations. While there are problems of attitude towards validation or knowledge and differences in social values among practitioners of these different disciplines, insights from each may help in designing researchable questions for others.

The problem of what does change in household behavior when women are educated has given rise to speculation. There seems to be a need for field observations to gain greater understanding of what goes on. This is more than a matter of scientific elegance or aesthetics. Preferred program policy design to reinforce certain behaviors, discourage others, or cope with potentially damaging behavior seems to require more insight than we now have.

If we have established reasonable ideas as to what sorts of education addressed to what targets and under what conditions protect and promote the health of populations of concern, we still need insights into how to promote such educational activities efficiently. Educational production functions are not readily at hand. UNESCO and other models do not seem addressed to these and there is also work to do here. 
108

\section{References}

Ram, Rati and Schultz, Theodore W. (1979). "Life span, health, savings, and productivity," Economic Development and Cultural Change 27: 399-421. 